\title{
Technical Definition of the TetraSpar Demonstrator Floating Wind Turbine Foundation
}

\author{
Michael Borg ${ }^{1}$, Morten Walkusch Jensen ${ }^{1}$, Scott Urquhart ${ }^{1}$, Morten Thøtt Andersen ${ }^{2}$, \\ Jonas Bjerg Thomsen ${ }^{2, *}$ and Henrik Stiesdal ${ }^{1}$ \\ 1 Stiesdal Offshore Technologies A/S; Nørrevoldgade 45, 5000 Odense C, Denmark; mbo@stiesdal.com (M.B.); \\ mwj@stiesdal.com (M.W.J.); sau@stiesdal.com (S.U); hst@stiesdal.com (H.S.) \\ 2 Department of the Built Environment, Aalborg University, Thomas Manns Vej 23, 9220 Aalborg Ø, Denmark; \\ mta@build.aau.dk \\ * Correspondence: jbt@build.aau.dk; Tel.: +45-9940-3758
}

Received: 17 August 2020; Accepted: 15 September 2020; Published: 18 September 2020

\begin{abstract}
With the deployment of the TetraSpar demonstrator, a significant cost-reduction is realized in the field of offshore floating wind turbines. The TetraSpar floating wind turbine foundation brings a milestone that emphasizes on a modular and fully industrialized foundation that consists of main components already widely available in the current wind energy supply chain. In an effort to provide an open approach to the development of the concept, this paper aims at giving a description of the design in order to enable an educated discussion of different design philosophies and their influence on material usage and production times. The description of the different subcomponents of the system should allow any entity to build a model for comparison and/or benchmarking any of their own findings against this concept. It is the authors' expectation that this open approach to technological discussion is paramount to obtaining continued cost-reduction in the area of floating offshore wind-for this concept and others.
\end{abstract}

Keywords: TetraSpar; demonstrator; floating wind turbine; technical description; technology overview

\section{Introduction}

In recent years, the wind energy sector has seen a rapid development, both onshore and offshore. The offshore alone has seen a growth from a cumulative capacity of around $2.5 \mathrm{GW}$ in 2009 to just over 22 GW in the end of 2019 [1]. It is obvious that this rate cannot continue neither onshore nor offshore as the most suitable and profitable locations are, as a consequence of the massive development, becoming scarcer. The move to offshore locations is motivated not only by the available open areas but also the improved wind resource of higher and more stable wind speeds. With the introduction of floating offshore wind turbine (FOWT) technology, a completely new and untapped market has opened up for the wind industry. As noted by the Carbon Trust [2], the share of the total offshore wind resource at water depths higher than $60 \mathrm{~m}$ in Europe, USA, and Japan is roughly $80 \%, 60 \%$, and $80 \%$, respectively.

A multitude of FOWT concepts have been presented and several have even been deployed in scaled demonstrator projects. Currently the market is picking up pace by presenting more than a dozen precommercial and fully commercial projects installed by 2022. The average rating of these projects resides around $28 \mathrm{MW}$ [3] and the technologies used are among others the WindFloat semisubmersible by Principle Power [4], Damping Pool barge by IDEOL [5], and the Hywind spar by Equinor [6].

Despite this positive development in FOWT concepts, there are still a number of challenges to be addressed for the industry to demonstrate commercial viability. First, current methods for fabrication and structural assembly of FOWT concepts require substantial manual operations and long time horizons. Besides the obvious cost challenge from this approach, it may also prove to be difficult to 
install commercial scale projects within the optimal timeframe of spring to autumn when metocean conditions are more favorable. In addition, current FOWT concepts have not yet been proven adequate for holding turbines in the $15 \mathrm{MW}+$ class, the size which is expected to be available at the time the FOWT market commercialized in the late 2020s. Finally, there remain several technical orientated challenges such as operation and maintenance concept and cost-effective mooring design.

The motivation behind the open access approach of the present paper is to provide industry insight to the TetraSpar Demonstration Floating Wind Turbine Foundation, a concept which addresses a number of these industry challenges. It is the authors opinion that this open information sharing is paramount for the FOWT sector since it enables an educated discussion between designers and better clarity for developers, funding bodies and policymakers, and hence ultimately bringing down the levelized cost of energy (LCOE).

\section{Design Requirements}

Besides providing sufficient static and dynamic stability for the wind turbine, there are a number of design criteria which can enable cost effective, large-scale deployment of FOWT for the commercial markets anticipated in the late 2020s:

- Design for scalable, industrialized production

- Key components should be scalable to accommodate turbines in the $15 \mathrm{MW}+$ scale, which is anticipated to be the average turbine size in the late 2020s when FOWT is commercialized.

- Components designed for industrialized production in order to capture benefits of learning curves and volume manufacturing.

- Minimize works to be done at port of embarkation

- Port space is often scarce and costs relatively high for storage and assembly of FOWTs, possibly becoming a limiting factor for widespread buildout of FOWT.

- In order to maintain pace of FOWT installation at the offshore site, fast component assembly and commissioning would be possible.

- Eliminate need for highly specialized, bespoke vessels

- One of the big upsides of FOWTs is the opportunity to utilize relatively small, local vessels and cranes for assembly and installation, making offshore wind more accessible for locations that are not near existing supply chain.

- Possibility to use relatively small, nonspecialized vessels also provides opportunity for increased local content in construction of offshore wind projects.

\section{TetraSpar Design Philosophy}

The main design philosophy behind the TetraSpar concept (cf. Figure 1) is the sole reliance on components that are highly suitable for industrialized mass production. For both the onshore and offshore wind energy sectors, the cost reductions in the tower structure have been key in bringing down the LCOE. This cost reduction has been made possible by substantial volume and standardized design allowing investments in highly industrialized production facilities. It is also important that the repeatability of lessons learnt on tower designs have not been hindered by any significant intellectual property rights.

To be able to reap the same fruits in the floating offshore wind industry, it is paramount that the design of any concept does not rely on any labor intensive tasks or quay-side production. All welding and coating works must be handled in tower production plants, where a controlled factory environment and automation allow for better tolerances and smaller safety factors. For the TetraSpar concept, this requirement is fulfilled by constructing modules that arrive at the port of embarkation ready for assembly by the already available workforce that is capable of assembling the wind turbine tower. This also implies that all assembly is of complexity equal to or less than the wind turbine tower, 
meaning primarily bolt and pin connections. The modularity of the TetraSpar concept allows for re-use of current logistics methods of the wind energy sector. No dimensions of the foundation elements exceeds those of the wind turbine, meaning that if the wind turbine can be delivered, then so can the foundation.

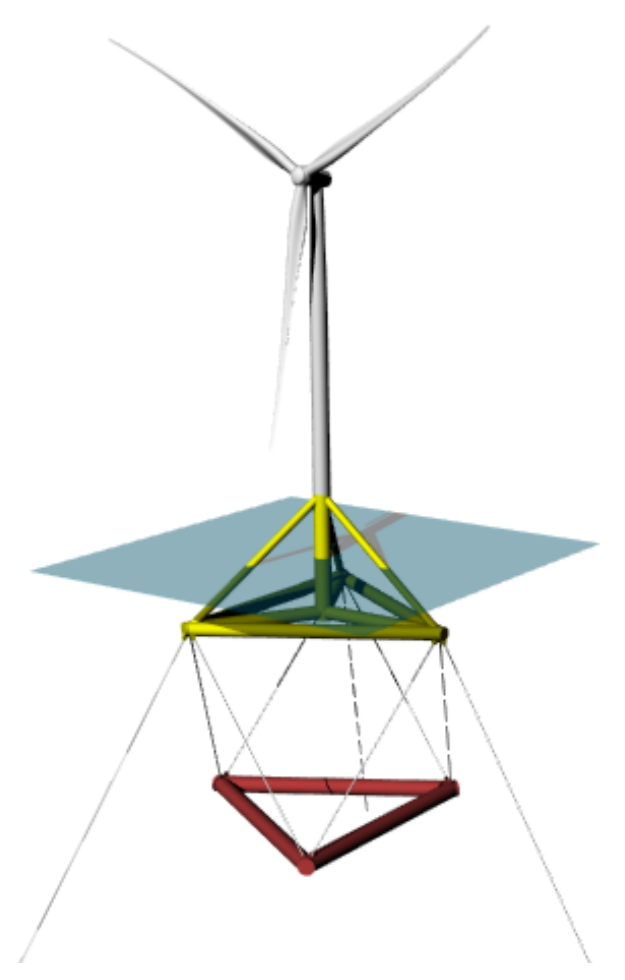

Figure 1. The TetraSpar concept.

The TetraSpar foundation and wind turbine can be fully assembled by land based lifting equipment, and subsequently precommissioning at quayside by regular onshore turbine crews. From that point and onwards, all installation works are handled by the small and abundant anchor handler vessels that have also preinstalled the mooring system. During towing, the foundation is highly buoyant and not fully ballasted with seawater until arriving at the site.

By adhering to this design philosophy, the TetraSpar demonstrator is expected to mark a step change in the LCOE of the FOWT sector, as detailed in [7]. The TetraSpar demonstrator has served as the first validation of relying on existing industrialized offshore wind supply chain for fabrication of a FOWT, with components now enroute for assembly at port.

\section{Demonstrator Site Description}

The TetraSpar floater will be moored at the Marine Energy Test Centre in the North Sea off the island of Karmøy on the western coast of Norway-approximately $1500 \mathrm{~m}$ north-west of the Equinor Hywind Demo, see Figure 2. 

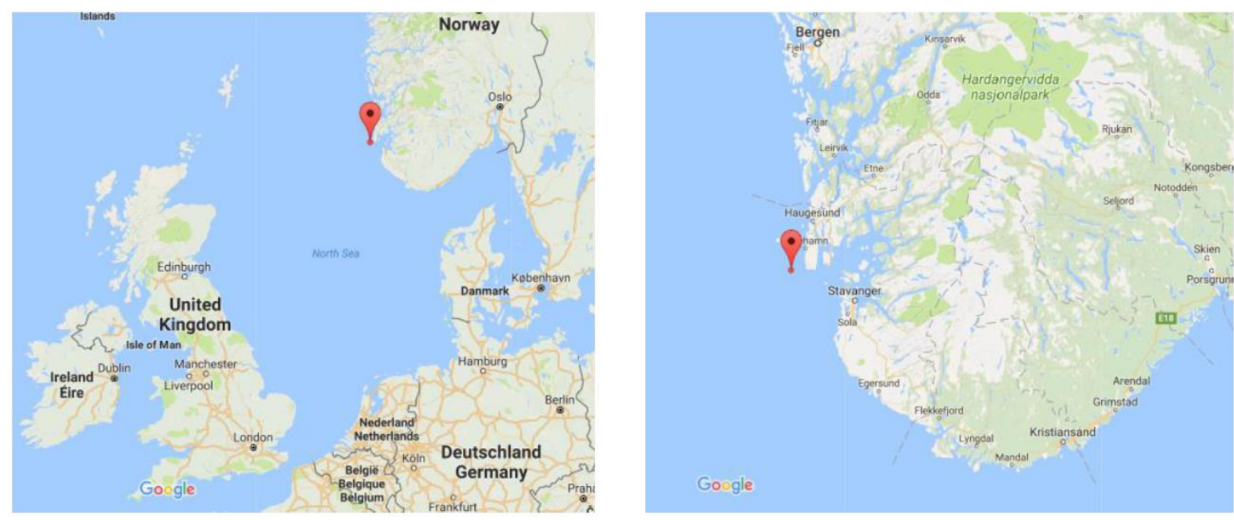

Figure 2. TetraSpar demonstrator project location.

\section{Metocean Conditions}

Extreme metocean conditions are defined in Table 1, while operational conditions are listed in Table 2. The extreme conditions are used in design of the structure, mooring system, and power cable, both to verify sufficient strength and to secure stability of the system. The accidental limit state (ALS) conditions in Table 1 correspond to a 1000-year wave event combined with 50-year wind and current. The sea state is used for evaluation of snap loads in suspension lines as well as other extreme excursion events.

In all cases, the turbulent wind can be modelled according to design requirements in, e.g., IEC-61400-1 [8]. The vertical wind speed variation is modelled by use of the NORSOK wind profile [9]. Based on site investigations, the waves are modelled with the Torsethaugen spectrum [10], while currents are considered constant in time.

Table 1. Extreme metocean conditions for ultimate limit state (ULS) calculations.

\begin{tabular}{lll}
\hline Item & Unit & Value \\
\hline Water depth & $(\mathrm{m})$ & $220.0 \mathrm{~m}$ \\
\hline \multicolumn{3}{c}{ ULS (50-year) } \\
\hline Wind speed at hub height & $(\mathrm{m} / \mathrm{s})$ & 45.9 \\
Significant wave height $\left(H_{s}\right)$ & $(\mathrm{m})$ & 12.9 \\
Peak wave period $\left(T_{p}\right)$ & $(\mathrm{s})$ & 16.0 \\
Current velocity & $(\mathrm{m} / \mathrm{s})$ & 1.7 \\
\hline \multicolumn{3}{c}{ ALS (1000-year) } \\
\hline Wind speed at hub height & $(\mathrm{m} / \mathrm{s})$ & 45.9 \\
Significant wave height $\left(H_{s}\right)$ & $(\mathrm{m})$ & 15.5 \\
Peak wave period $\left(T_{p}\right)$ & $(\mathrm{s})$ & 17.5 \\
Current velocity & $(\mathrm{m} / \mathrm{s})$ & 1.9 \\
\hline
\end{tabular}

Table 2. Operational metocean conditions for fatigue limit state (FLS) calculations. Three peak wave periods are defined corresponding to the mean value of the probability sectors defined by the values in the indices.

\begin{tabular}{|c|c|c|c|c|c|c|c|c|c|c|c|c|c|}
\hline \multirow{2}{*}{$\begin{array}{l}\text { Item } \\
\text { Wind speed at hub height }\end{array}$} & \multirow{2}{*}{$\begin{array}{l}\text { Unit } \\
(\mathrm{m} / \mathrm{s})\end{array}$} & \multicolumn{12}{|c|}{ Value } \\
\hline & & 4.00 & 6.0 & 8.00 & 10.00 & 12.00 & 14.00 & 16.00 & 18.00 & 20.00 & 22.00 & 24.00 & 26.00 \\
\hline Wave height $\left(H_{S}\right)$ & $(\mathrm{m})$ & 0.64 & 0.95 & 1.31 & 1.71 & 2.15 & 2.64 & 3.15 & 3.70 & 4.27 & 4.87 & 5.50 & 6.16 \\
\hline Wave period $\left(T_{p, 0-25}\right)$ & (s) & 4.82 & 5.20 & 5.59 & 5.99 & 6.41 & 6.91 & 7.35 & 7.86 & 8.31 & 8.84 & 9.37 & 9.90 \\
\hline Wave period $\left(T_{p, 25-75}\right)$ & (s) & 7.51 & 7.88 & 8.28 & 8.64 & 9.01 & 9.42 & 9.78 & 10.19 & 10.60 & 11.01 & 11.42 & 11.87 \\
\hline Wave period $\left(T_{p, 75-100}\right)$ & (s) & 11.86 & 12.09 & 12.39 & 12.58 & 12.76 & 12.94 & 13.11 & 13.29 & 13.56 & 13.75 & 13.95 & 14.25 \\
\hline Current velocity & $(\mathrm{m} / \mathrm{s})$ & 0.12 & 0.19 & 0.25 & 0.32 & 0.39 & 0.45 & 0.52 & 0.59 & 0.66 & 0.73 & 0.80 & 0.87 \\
\hline
\end{tabular}




\section{Global System Overview}

The foundation consists of a floating platform moored to the seabed with a catenary mooring system. The floating platform consists of the floater structure and the keel structure, which is suspended below the floater with a number of lines. The arrangement is illustrated in Figure 1 and definition of coordinate system in Figure 3.

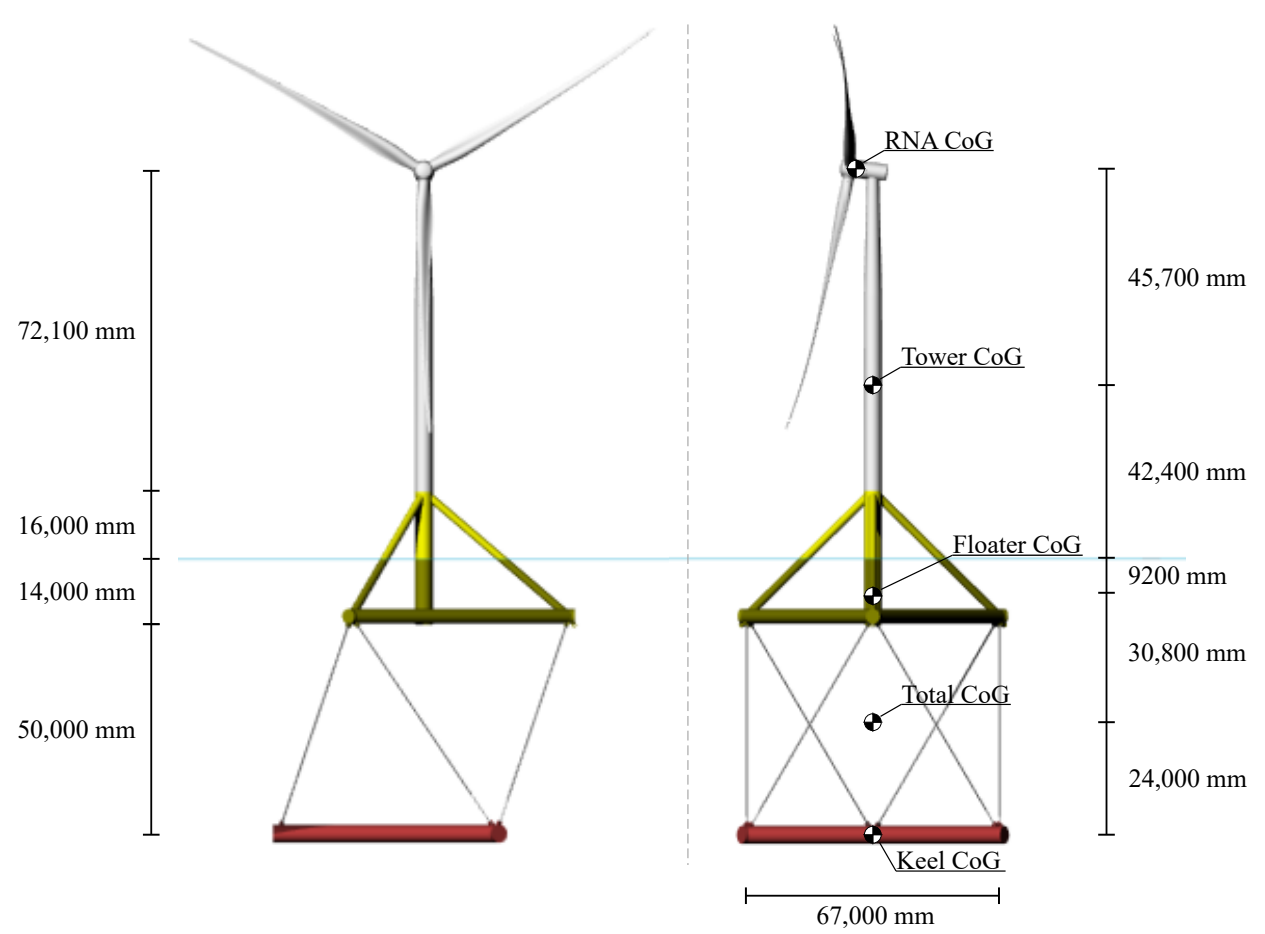

Figure 3. Definition of structure and centre of gravity (CoGs).

The floater and the keel are constructed out of a series of steel tubes, connected together by nodes. The floater consists of a vertical central column where three horizontal radial braces are connected close to its base, oriented 120 degrees from one another. At the outer end of each of these radial braces, a diagonal brace is connected to the central column. Further, adjacent radial braces outer ends are connected by lateral braces (cf. Figure 4 for naming convention).

Lastly, the keel suspension lines and mooring lines are also connected to the radial braces outer nodes. The keel consists of three tubes connected together to form a triangular shape and is suspended below the floater with six suspension lines.

This configuration effectively gives the TetraSpar the properties of a spar, having a significant buoyancy and achieving stability via the ballast represented by the keel. With variations in the keel mass and depth the total system properties can be tuned to match the desired response of any design. The overall properties of the floater foundation are listed in Table 3. Detailed properties of all components are presented in the following sections.

Table 3. Overall properties of the global system.

\begin{tabular}{lll}
\hline Item & Unit & Value \\
\hline Overall mass incl. ballast & (tons) & 5471 \\
Overall vertical center of gravity below MWL & (m) & 40.0 \\
Draft & (m) & 66.0 \\
Height of foundation-tower interface, above MWL & (m) & 16.0 \\
\hline
\end{tabular}




\section{Component Description}

The TetraSpar demonstrator is a combination of the floater, keel, suspension system, mooring, and wind turbine. Each part is described in the following sections with necessary information on mechanical and structural properties. The sections provide sufficient data for modelling the total TetraSpar FOWT system. Due to simplicity, all structural elements are modelled as uniform cylinders with an equivalent length ensuring the buoyancy of the actual structure.

\subsection{Floater}

In general, the floater consists of ten individual components, distributed among four unique structural elements. The naming convention for the components of the floater is given in Figure 4 . These elements are terminated in cast nodes and conically tapered where applicable. All nodes are connected with shear loaded pin connections in order to mitigate the risk of possible errors in works related to bolt tensioning. The overall description of the floater is presented in Table 4, while the definition of the position and properties of each component is listed in Table 5. The conically tapered ends are converted into constant cylinders providing similar buoyancy of the entire element. The floater is equipped with boat landing, platforms, wind turbine components, etc., all included in the mass defined in Table 4.

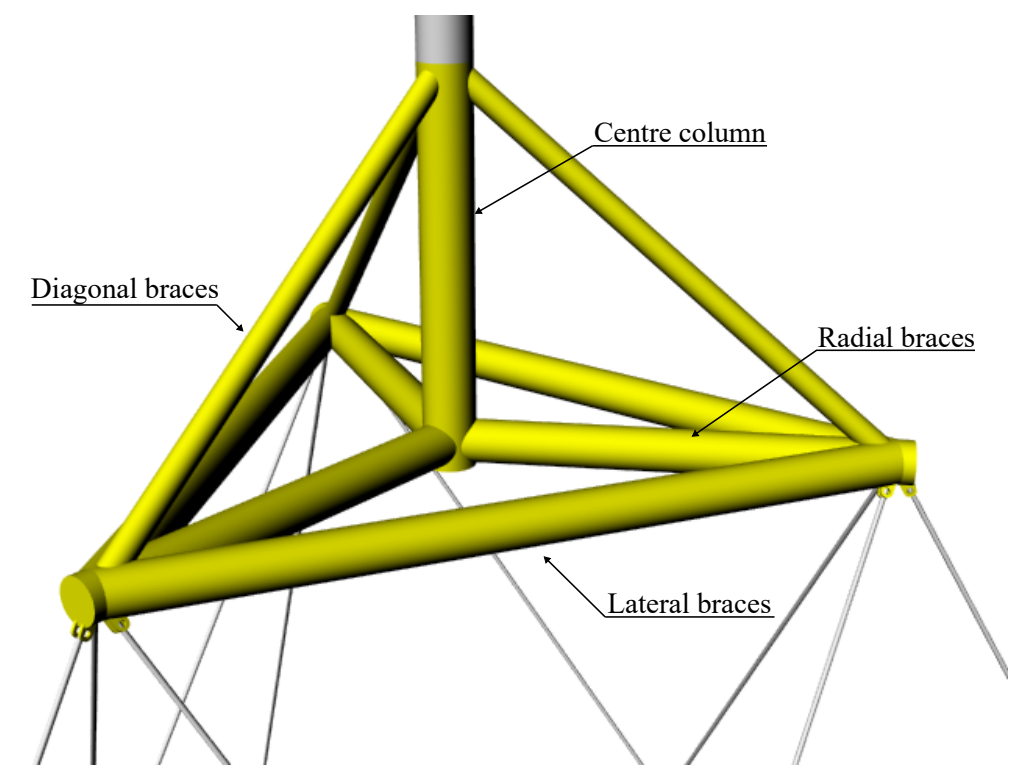

Figure 4. Naming of floater subcomponents.

Table 4. Properties of the floater.

\begin{tabular}{lll}
\hline Item & Unit & Value \\
\hline Floater mass incl. ballast water and additional components & $($ tons $)$ & 1340 \\
Floater vertical center of gravity wrt. MWL & $(\mathrm{m})$ & -9.2 \\
Distance from MWL to bottom of floater & $(\mathrm{m})$ & 16.0 \\
Floater roll mass moment of inertia wrt. CoG & $\left(\mathrm{kgm}^{2}\right)$ & $442.5 \times 10^{6}$ \\
Floater pitch mass moment of inertia wrt. CoG & $\left(\mathrm{kgm}^{2}\right)$ & $442.2 \times 10^{6}$ \\
Floater yaw mass moment of inertia wrt. CoG & $\left(\mathrm{kgm}^{2}\right)$ & $532.2 \times 10^{6}$ \\
\hline
\end{tabular}


Table 5. Definition of component position and dimensions.

\begin{tabular}{lll}
\hline Item & Unit & Value \\
\hline Center column diameter & $(\mathrm{m})$ & 4.3 \\
Center column equivalent length & $(\mathrm{m})$ & 30.6 \\
Center column coordinates wrt. MWL & $(\mathrm{m})$ & $(0.0 ; 0.0 ;-14.6)-(0.0 ; 0.0 ; 16.0)$ \\
\hline Radial brace diameter & (m) & 3.5 \\
Radial brace equivalent length & (m) & 32.8 \\
Radial brace mode coordinates wrt. MWL & (m) & $(2.5 ; 0.0 ;-14.0)-(35.3 ; 0.0 ;-14.0)$ \\
& & $(-1.2 ; 2.2 ;-14.0)-(-17.6 ; 30.6 ;-14)$ \\
& & $(-1.2 ;-2.2 ;-14)-(-17.6 ;-30.6 ;-14)$ \\
\hline Diagonal brace diameter & (m) & 2.2 \\
Diagonal brace equivalent length & (m) & 38.9 \\
Diagonal brace node coordinates wrt. MWL & (m) & $(3.1 ; 0.0 ; 14.1)-(32.4 ; 0.0 ;-11.5)$ \\
& & $(-1.5 ; 2.7 ; 14.1)-(-16.2 ; 28.0 ;-11.5)$ \\
& & $(-1.5 ;-2.7 ; 14.1)-(-16.2 ;-28.0 ;-11.5)$ \\
\hline Lateral brace diameter & (m) & 4.0 \\
Lateral brace equivalent length & (m) & 49.2 \\
Lateral brace node coordinates wrt. MWL & (m) & $(30.5 ; 3.5 ;-14.0)-(-12.2 ; 28.1 ;-14.0)$ \\
& & $(-18.3 ; 24.6 ;-14.0)-(-18.3 ;-24.6 ;-14)$ \\
& & $(-12.2 ;-28.1 ;-14.0)-(30.5 ;-3.5 ;-14.0)$ \\
\hline
\end{tabular}

\subsection{Keel}

The keel consists of three identical cylinders combined in a triangular shape as shown in Figure 5. Similar to the elements in the floater, the cylinders in the keel are conically tapered, but here simplified into constant cylinders. The total keel system characteristics are listed in Table 6, together with description of the individual cylinders.

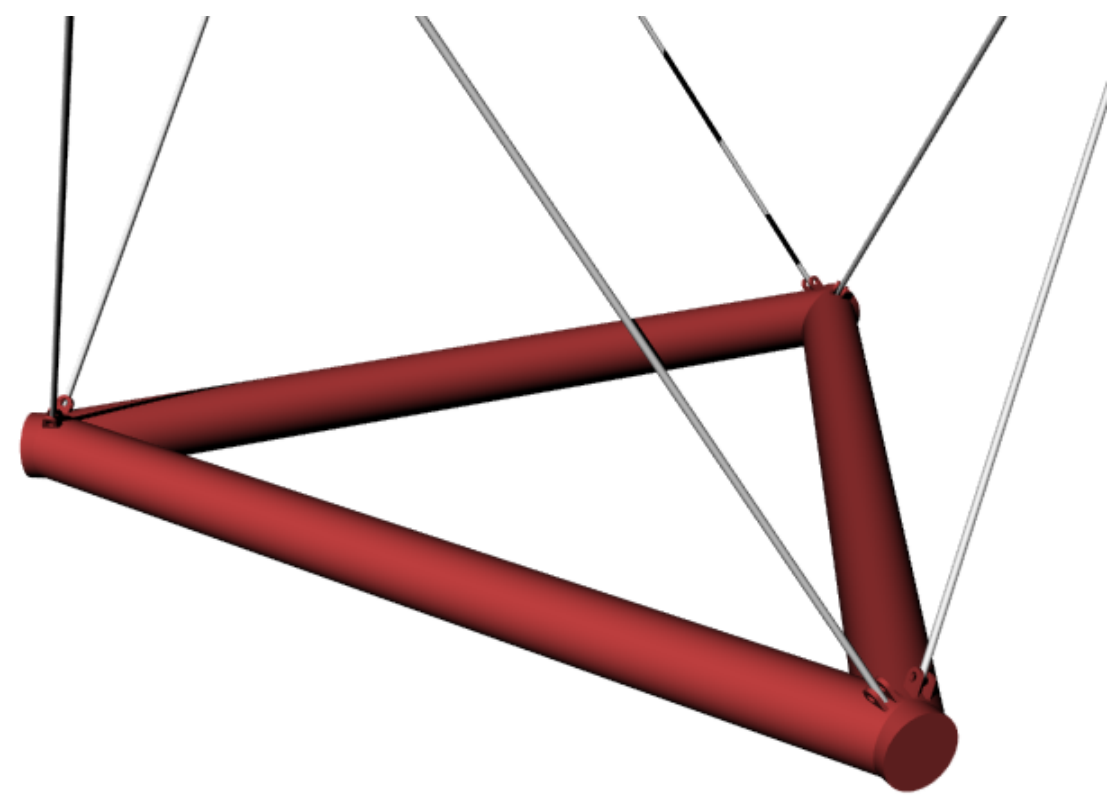

Figure 5. Illustration of the keel. 
Table 6. Properties of the keel structure.

\begin{tabular}{lll}
\hline Item & Unit & Value \\
\hline Keel mass incl. ballast water & $($ tons $)$ & 3696 \\
Vertical distance from MWL to keel horizontal centerline & $(\mathrm{m})$ & 64.0 \\
Keel roll mass moment of inertia wrt. CoG & $\left(\mathrm{kgm}^{2}\right)$ & $1.443 \times 10^{9}$ \\
Keel pitch mass moment of inertia wrt. CoG & $\left(\mathrm{kgm}^{2}\right)$ & $1.443 \times 10^{9}$ \\
Keel yaw mass moment of inertia wrt. CoG & $\left(\mathrm{kgm}^{2}\right)$ & $2.878 \times 10^{9}$ \\
Keel equivalent cylinder length & $(\mathrm{m})$ & 56.4 \\
Keel cylinder diameter & $(\mathrm{m})$ & 4.1 \\
Keel brace node coordinates wrt. MWL & $(\mathrm{m})$ & $(20.0 ;-28.2 ;-64.0)-(20.0 ; 28.2 ;-64.0)$ \\
& & $(14.4 ; 31.4 ;-64.0)-(-34.4 ; 3.2 ;-64)$ \\
& & $(-34.4 ;-3.2 ;-64.0)-(14.4 ;-31.4 ;-64.0)$ \\
\hline
\end{tabular}

\subsection{Suspension System}

The keel is suspended from the floater through six lines. Each line is composed of a bundle of synthetic ropes. The mechanical properties of the line type are presented in Table 7.

Table 7. Mechanical properties of the suspension lines, with definition of fairlead coordinates and line connectivity.

\begin{tabular}{|c|c|c|}
\hline Item & Unit & Value \\
\hline Linetype & $(-)$ & Synthetic rope bundle \\
\hline Buoyancy diameter & $(\mathrm{mm})$ & 119.0 \\
\hline Unstretched length & $(\mathrm{m})$ & 60.0 \\
\hline Submerged mass & $(\mathrm{kg} / \mathrm{m})$ & -0.44 \\
\hline Dry mass & $(\mathrm{kg} / \mathrm{m})$ & 11.0 \\
\hline Axial Stiffness & $(\mathrm{kN})$ & $506,667.0$ \\
\hline \multicolumn{3}{|c|}{ Floater Suspension (FS) fairlead coordinates (wrt. MWL) } \\
\hline FS1 & $(\mathrm{m})$ & $(35.6 ;-1.2 ;-15.8)$ \\
\hline FS2 & $(\mathrm{m})$ & $(-16.8 ;-31.5 ;-15.8)$ \\
\hline FS3 & $(\mathrm{m})$ & $(-18.8 ;-30.3 ;-15.8)$ \\
\hline FS4 & $(\mathrm{m})$ & $(-18.8 ; 30.3 ;-15.8)$ \\
\hline FS5 & $(\mathrm{m})$ & $(-16.8 ; 31.4 ;-15.8)$ \\
\hline FS6 & $(\mathrm{m})$ & $(35.6 ; 1.2 ;-15.8)$ \\
\hline \multicolumn{3}{|c|}{ Keel fairlead (KF) coordinates (wrt. MWL) } \\
\hline KF1 & $(\mathrm{m})$ & $(19.8 ;-32.7 ;-64.0)$ \\
\hline KF2 & $(\mathrm{m})$ & $(18.4 ;-33.5 ;-64.0)$ \\
\hline KF3 & $(\mathrm{m})$ & $(-38.2 ;-0.8 ;-64.0)$ \\
\hline KF4 & $(\mathrm{m})$ & $(-38.2 ; 0.8 ;-64.0)$ \\
\hline KF5 & (m) & $(18.4 ; 33.5 ;-64.0)$ \\
\hline KF6 & $(\mathrm{m})$ & $(19.8 ; 32.7 ;-64.0)$ \\
\hline \multicolumn{3}{|c|}{ Connectivity } \\
\hline Suspension line 1 & & FS1-KF1 \\
\hline Suspension line 2 & & FS2-KF2 \\
\hline Suspension line 3 & & FS3-KF3 \\
\hline Suspension line 4 & & FS4- KF4 \\
\hline Suspension line 5 & & FS5-KF5 \\
\hline Suspension line 6 & & FS6-KF6 \\
\hline
\end{tabular}

\subsection{Mooring System}

The TetraSpar demonstrator utilizes a classic 3-line spread mooring system for station keeping. The general mooring description and line mechanical properties can be seen in Tables 8 and 9 respectively. To account for dominant environmental load directions, the lines are unevenly 
distributed. The total mooring system and floater orientation in the table is not aligned with the actual onsite-orientation. Figure 6 shows the mooring line catenary at the static state.

Table 8. Mooring system description.

\begin{tabular}{lll}
\hline Item & Unit & Value \\
\hline Anchor radius & $(\mathrm{m})$ & 630.0 \\
Anchor node coordinates wrt. MWL & $(\mathrm{m})$ & $(630.0 ; 0.0 ;-220.0)$ \\
& & $(-215.5 ;-592.0 ;-220.0)$ \\
& & $(-315.0 ; 545.6 ;-220.0)$ \\
Mooring fairlead node coordinates wrt. MWL & $(\mathrm{m})$ & $(36.3 ; 0.0 ;-12.4)$ \\
& & $(-18.1 ;-31.4 ;-12.4)$ \\
& & $(-18.1 ; 31.4 ;-12.4)$ \\
\hline & & \\
& Segment lengths of each & mooring line \\
\hline Fairlead & $(-)$ \\
Linetype1 & $(\mathrm{m})$ & 80.0 \\
Linetype2 & $(\mathrm{m})$ & 6.0 \\
Linetype1 & $(\mathrm{m})$ & 140.0 \\
Linetype3 & $(\mathrm{m})$ & 145.5 \\
Linetype4 & $(\mathrm{m})$ & 30.0 \\
Linetype2 & $(\mathrm{m})$ & 270.0 \\
Anchor & $(-)$ & \\
\hline
\end{tabular}

Table 9. Mechanical properties of the mooring system line types.

\begin{tabular}{lll}
\hline Item & Unit & \multicolumn{1}{c}{ Value } \\
\hline & \multicolumn{2}{c}{ Linetype1 } \\
\hline Linetype & $(-)$ & Synthetic rope \\
Buoyancy diameter & $(\mathrm{mm})$ & 108.0 \\
Submerged weight & $(\mathrm{N} / \mathrm{m})$ & 2.2 \\
Axial Stiffness & $(\mathrm{kN})$ & $4.45 \times 10^{5}$ \\
\hline & \multicolumn{2}{c}{ Linetype2 } \\
\hline Linetype & $(-)$ & Mooring chain \\
Buoyancy diameter & $(\mathrm{mm})$ & 202 \\
Submerged weight & $(\mathrm{N} / \mathrm{m})$ & 2139.6 \\
Axial Stiffness & $(\mathrm{kN})$ & $1.15 \times 10^{6}$ \\
\hline & \multicolumn{2}{c}{ Linetype3 } \\
\hline Linetype & $(-)$ & Mooring chain \\
Buoyancy diameter & $(\mathrm{mm})$ & 234 \\
Submerged weight & $(\mathrm{N} / \mathrm{m})$ & 2872.0 \\
Axial Stiffness & $(\mathrm{kN})$ & $1.55 \times 10^{6}$ \\
\hline & \multicolumn{2}{c}{ Linetype4 } \\
\hline Linetype & $(-)$ & Mooring chain w. clump weights \\
Buoyancy diameter & $(\mathrm{mm})$ & 698 \\
Submerged weight & $(\mathrm{N} / \mathrm{m})$ & $19,515.0$ \\
Axial Stiffness & $(\mathrm{kN})$ & $1.06 \times 10^{6}$ \\
\hline
\end{tabular}




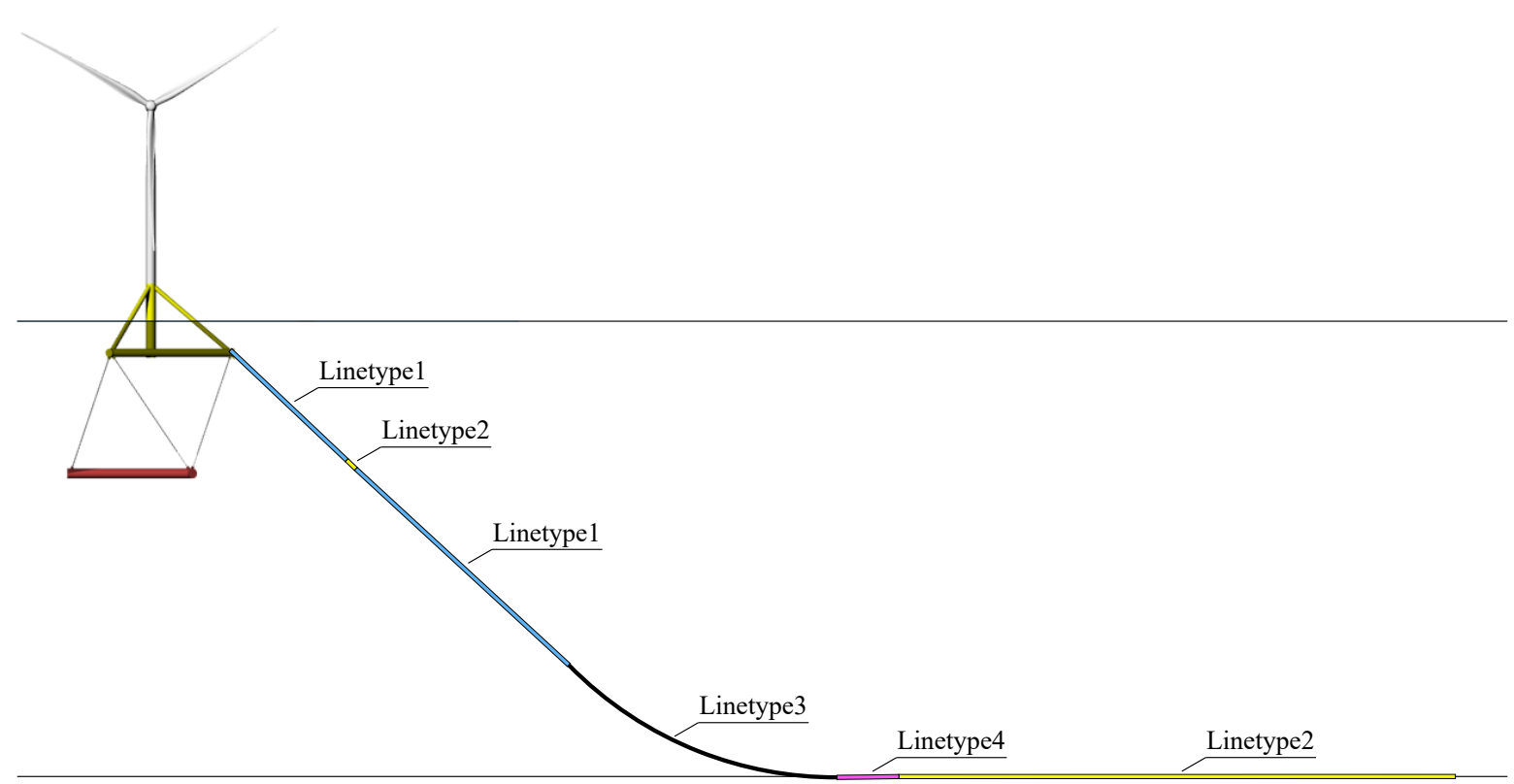

Figure 6. Mooring segments overview.

\subsection{Wind Turbine}

The TetraSpar demonstrator is equipped with a Siemens 130-3.6 MW wind turbine. The detailed description of the RNA is not publicly available but can be modelled as a clump mass using the values in Table 10. The tower is modelled as a conical element with properties as listed in the table.

Table 10. Wind turbine properties.

\begin{tabular}{lll}
\hline Item & Unit & Value \\
\hline Tower base above MWL & $(\mathrm{m})$ & 16.0 \\
Rotor and nacelle (RNA) mass & $($ tons $)$ & $\sim 200.0$ \\
RNA CoG wrt. tower base & $(\mathrm{m})$ & $(3.75 ; 0.0 ; 72.1)$ \\
Total tower mass & $($ tons $)$ & 235 \\
Vertical tower CoG above tower base & $(\mathrm{m})$ & 26.4 \\
Tower length & $(\mathrm{m})$ & 71.6 \\
Tower roll MoI wrt. CoG & $\left(\mathrm{kgm}^{2}\right)$ & $89.38 \times 10^{6}$ \\
Tower pitch MoI wrt. CoG & $\left(\mathrm{kgm}^{2}\right)$ & $89.38 \times 10^{6}$ \\
Tower yaw MoI wrt. CoG & $\left(\mathrm{kgm}^{2}\right)$ & $489.85 \times 10^{3}$ \\
Tower base diameter & $(\mathrm{m})$ & 4.3 \\
Tower top diameter & $(\mathrm{m})$ & 3.6 \\
\hline
\end{tabular}

\section{Conclusions}

With the fabrication of the TetraSpar Demonstrator foundation nearing its completion, a milestone is reached in the sector of floating offshore wind turbines. This milestone marks the switch from one-of foundations based on the oil and gas industry high-margin approach to a more modular and fully industrialized foundation based solely on main components already widely available in the current wind energy supply chain. Hence this milestone also makes a completely new outlook on the CAPEX levels to be expected in the coming years.

This paper has presented a technical description of the main properties of the full demonstrator ranging from design conditions to specific design choices on wind turbine, foundation members, and mooring system. This level of detail should allow for colleagues in both industry and academia to make comparative studies on both technical solutions as well as cost estimates. It is the expectation of 
the authors that this open design approach is necessary to accelerate the development of the coming generation of floating wind turbine foundations, and hence would like to invite other main contributors in the sector to add to this discussion in order to obtain the most transparent and positive outlook of the sector as possible.

Author Contributions: M.B., M.W.J., S.U., H.S., M.T.A. and J.B.T. provided technical inputs; M.B., M.T.A., and J.B.T. drafted the paper; M.B., M.W.J., S.U., H.S., M.T.A. and J.B.T. reviewed the paper; J.B.T. finalized the paper. All authors have read and agreed to the published version of the manuscript.

Funding: This research was partially funded by the Energy Technology Development and Demonstration Program (EUDP) through the project TetraSpar (Grant number 64017-05171).

Conflicts of Interest: The authors declare no conflict of interest.

\section{References}

1. Walsh, C.; Ramírez, L.; Fraile, D.; Brindley, G. Offshore Wind in Europe-Key Trends and Statistics 2019; Wind Europe: Brussels, Belgium, 2020.

2. Carbon Trust. Floating Offshore Wind: Market and Technology Review. 2015. Available online: https:/ / www.carbontrust.com/resources/floating-offshore-wind-market-technology-review (accessed on 10 July 2020).

3. WindEurope. Floating Offshore Wind Energy: A Policy Blueprint for Europe. 2018. Available online: https://windeurope.org/policy/position-papers/floating-offshore-wind-energy-a-policy-blueprint-for-euro pe/ (accessed on 25 March 2020).

4. Principle Power, Inc. WindFloat. Available online: http://http://www.principlepowerinc.com/en/windfloat (accessed on 3 June 2020).

5. IDEOL. Floating Offshore Wind. Available online: https://www.ideol-offshore.com/en (accessed on 3 June 2020).

6. Equinor. Hywind. Available online: https://www.equinor.com/en/what-we-do/floating-wind/how-hywindworks.html (accessed on 3 June 2020).

7. Andersen, M.T.; Tetu, A.; Stiesdal, H. Economic Potential of Industrializing Floating Wind Turbine Foundations. In Proceedings of the ASME 2018 37th International Conference on Ocean, Offshore and Arctic Engineering. American Society of Mechanical Engineers, Madrid, Spain, 17-22 June 2018.

8. IEC. IEC 61400-1:2019 Wind Energy Generation Systems-Part 1: Design Requirements; IEC: Geneva, Switzerland, 2019.

9. Standards Norway. NORSOK Standard N-003: Actions and Action Effects; Standards Norway: Lysaker, Norway 2007.

10. Torsethaugen, K.; Haver, S. Simplified double peak spectral model for ocean waves. In Proceedings of the Fourteenth International Offshore and Polar Engineering Conference, Toulon, France, 23-28 May 2004.

(C) 2020 by the authors. Licensee MDPI, Basel, Switzerland. This article is an open access article distributed under the terms and conditions of the Creative Commons Attribution (CC BY) license (http://creativecommons.org/licenses/by/4.0/). 